\title{
Effects of Road Maintenance on Vehicle Emissions Evaluating by the Model of Highway Development and Management
}

\author{
Mengran Zhang \\ School of Civil Engineering, University of Birmingham, Edgbaston Birmingham, B15 2TT, UK \\ sola0324@hotmail.com
}

Keywords: Highway Development and Management; Emission models; Road Maintenance Abstract. Vehicle emission is nowadays a significant source of climate change and air pollution. In order to control vehicle emissions, road maintenance is considered as one of the controlling method. Hence, it is necessary to find out how maintenance effects on vehicle emissions. Model of Highway Development and Management (HDM-4) emission model is used to set up a sample project to demonstrate how maintenance effects on vehicle emissions.

\section{Introduction}

Climate change has become one of greatest environmental problems nowadays in a short time period with alarming speed. As vehicles produce a large amount of greenhouse gas (GHG), vehicle emissions can be a vital element of climate change, especially Carbon Dioxide $\left(\mathrm{CO}_{2}\right)^{[1]}$. Therefore, it is important to find out how to reduce vehicle emissions in road engineering works.

The Highway Development and Management (HDM-4) model can predict the vehicle emissions during an analysis. For different road quality (different level of road maintenance), the amount of vehicle emissions is different. Compare these vehicle emissions for different road quality using HDM-4, and then it is apparent how road maintenance effects vehicle emissions.

HDM-4 model, which is developed by World Bank, is globally used as a planning, programming and preparation tool for the highway improvement and maintenance activities. It is a computer model to simulate physical and economic conditions of highway during the analysis period for the series of alternatives and scenarios specified by the user ${ }^{[2]}$. HDM-4 models can be mainly classified into two parts: Road Deterioration \&Works Effects (RDWE) models and Road User Effects (RUE) models. For Road Deterioration \&Works Effects models, pavement distress models are included. For Road User Effects models, they consists of travel time, vehicle operation, accidents and emission effects models ${ }^{[3]}$.

In this work, the emission effects models are the main part we focus on. In the HDM4 vehicle emission models, there are 7 types of the exhaust emissions: Hydrocarbon (HC), Carbon Monoxide (CO), Nitrogen Oxide (NOx), Sulphur Dioxide $\left(\mathrm{SO}_{2}\right)$, Carbon Dioxide $\left(\mathrm{CO}_{2}\right)$, Particulate Matters $(\mathrm{PM})$ and Lead $(\mathrm{Pb})$. In order to model the vehicle emissions, traffic volume and its components, type and geometry of the road section, vehicle operating speed, fuel type and vehicle life are needed as main characteristics ${ }^{[4]}$. 


\section{Methodology}

In order to implement HDM4 vehicle emission model, a number of input elements should be determined. These are as follows: Vehicle fleet, Configuration, Type and geometry of the road section, Traffic volume and its composition, Maintenance Standards, and Project.

\section{Vehicle Fleet}

The vehicle fleet for this work is selected as predefined England Vehicle Fleet. It has been input into HDM4 model under Vehicle fleet folder for the modeling. The vehicle fleet data contains the emission model parameter values introduced in Chapter 1 for the prediction of vehicle emissions.

\section{Configuration}

Before defining the road sections, it is necessary to create the speed flow types and traffic flow pattern if they do not exist. For this research project, the speed flow type is two lane roads, while the traffic flow pattern is free-flow.

As for High Traffic-AMAP and Low Traffic-AMAP, the default data for calibration set in HDM4 are used. However, for Medium-AMAP, the modified value is defined between High Traffic-AMAP and Low Traffic-AMAP in this project.

As for the climate zone, the England Climate under Climate Zone folder need to be created. According to Met Office, mean monthly precipitation in UK is $75 \mathrm{~mm}$, mean temperature for a whole year is about $10^{\circ} \mathrm{C}$ and average temperature is $14^{\circ} \mathrm{C}$. Therefore, the value of climate zone is defined.

\section{Type and Geometry of the Road Section}

For this work, the sample road section needs to be defined in order to demonstrate how maintenance investment effect on vehicle emission. There are two approaches can be used for this purpose. The first one is to locate some real data for an exist road section to do the analysis, while the second one is to assume some data for a typical road section to present and compare the effect of different level of maintenance on vehicle emissions. Although the latter one will not output with existing vehicle emission condition for a real road, the results of the latter approach will highlight the effect of the road investment on a number of typical sections for comparing, which also may be present in a real network. Based on these, this research project will adopt the latter approach for analysis.

With regard to the road condition for the road sample, the default data in HDM4 is used for the fair condition.

\section{Traffic Volume}

According to the given England Vehicle Fleet, there are 10 types of vehicles and no annual growth for each vehicle fleet.

\section{Maintenance Standards}

After data input of different typical road sections, the maintenance standards have to be defined in order to present how maintenance effects on vehicle emissions. For this modeling work, three maintenance standards are determined on behalf of good maintenance, fair maintenance and poor maintenance respectively. The works of poor maintenance include patching, crack sealing and resealing. As for works of fair maintenance, they are edge repair, patching, crack sealing and surface dressing. The works of good maintenance are routine edge repair, routine patching, crack sealing and thin overlay. In addition, the intervention level of good maintenance works is highest, while the one of poor maintenance works is lowest. After HDM4 analysis, the output of vehicle emission data should be different between good maintenance, fair maintenance and poor maintenance. 


\section{Project}

The last work for the modeling is to set up project by adding maintenance for typical road section. Since the project is to compare the vehicle emission output between different sections, "analysis by section" should be used. In addition, the start year of the project is 2015, while the analysis period is assumed as 20 years in order to realize the change of vehicle emissions in 20 years, which is useful for the result analysis. Selecting the Emissions model in HDM4 and running the analysis, the vehicle emissions can be predicted by the software automatically.

\section{Results}

After the modeling, HDM4 generate the output report about traffic, deterioration/work effects, road user effects, environmental effects, cost streams and economic evaluation, etc. For this research project "Road Investment Effects on Vehicle Emission using HDM4", the outputs about deterioration/work effects and environmental effects can be used to analyze how maintenance investment effects on vehicle emissions. These are the useful report generated by HDM4 software: (1) Deterioration/Work Effects: Average Roughness by Project (Graph), Average Roughness by Section (Graph), Road Works Summary (by Section), (2) Environmental Effects: Emissions Summary.

\section{Road Maintenance and Road Condition}
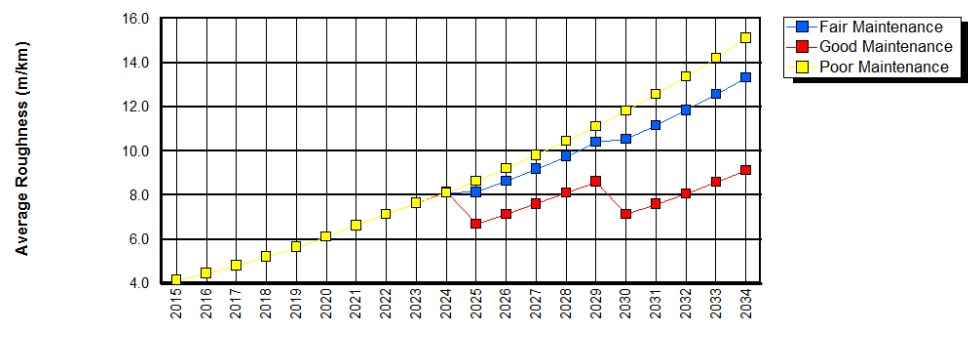

Year

Fig.1 Average Roughness (IRIav) for Typical Road Section

As mentioned in Chapter 2.5, three maintenance standards are set up on behalf of good maintenance, fair maintenance and poor maintenance. As the result, different level of maintenance directly impacts on the road condition, which further influences the fuel consumption resulting in production of vehicle emissions through traffic speed, longer journey times, "stop-start" cycles or other factors. The average roughness of typical road (assumed) section through $2 \mathrm{~B}$ years is shown as Fig. 1.
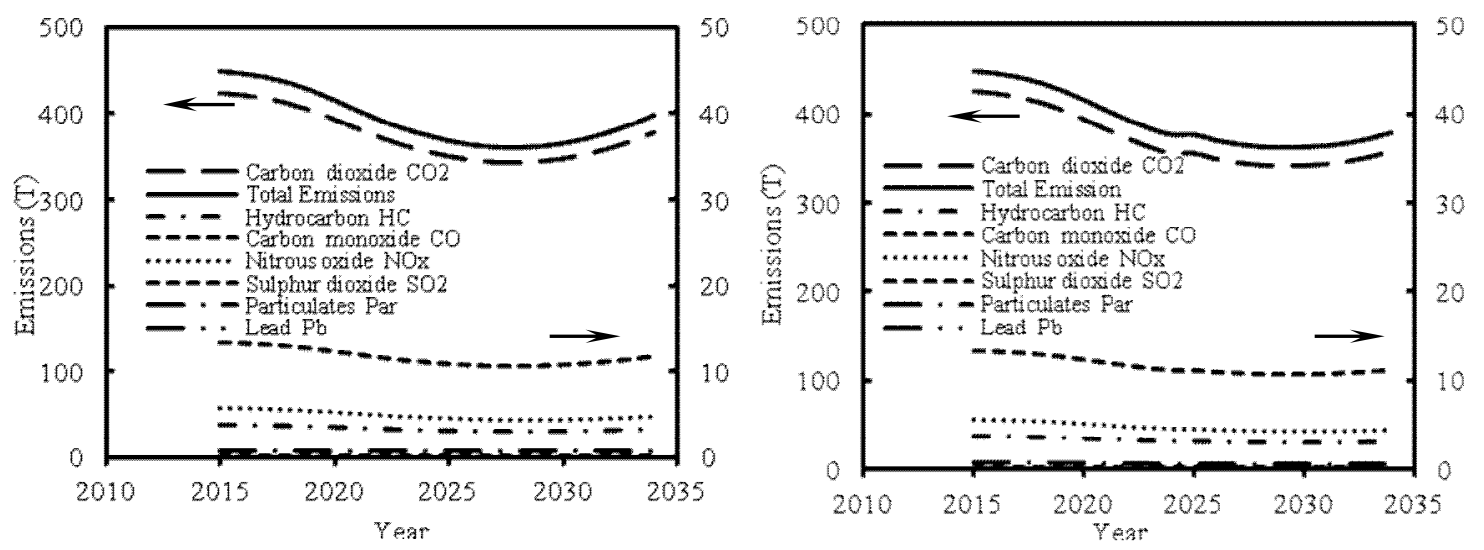


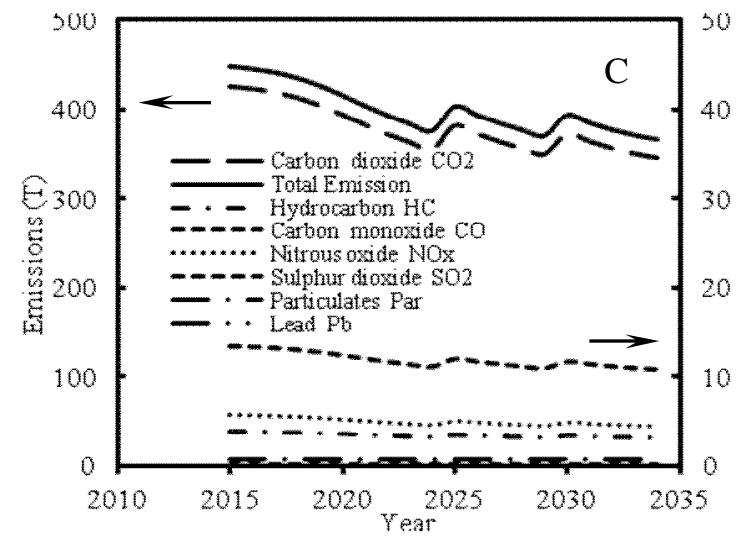

Fig.2 Vehicle Emissions for "Traffic-One" Section under Poor (A), Fair (B) and Good (C) Maintenance

From the figure, it is obvious that the roughness of typical road section under all the maintenances will increase, which also means that the road section under all the maintenance will deteriorate over next 20 years. The roughness under poor, good and fair maintenance from 2015 to 2023 is absolutely the same. However, the deterioration level after 2024 for different maintenance are various from each other. According to the average roughness graph, poor maintenance with lowest intervention level and least work items among these three maintenances will lead to most deterioration for the road sections, from 4.0 IRI in 2015 to 15.2 IRI in 2034. It is because that only patching, crack sealing and resealing will be implemented for poor maintenance and the effects of these work items are inconspicuous. As for good maintenance, the road section will deteriorate least, from 4.0 IRI in 2015 to 8.8 in 2034. In addition, the average roughness of the road section under good maintenance fluctuates a lot, which due to the effectiveness of overlay every five years. The deterioration level of road sections under fair maintenance is between good maintenance and poor maintenance, from 4.0 IRI in 2015 to 13.3 IRI. Surface dressing implemented in 2025 and 2030 makes the road roughness damage less, comparing with road under poor maintenance.

\section{Vehicle Emissions}

According to Emissions Summary, annual emission qualities in tonnes have been predicted by HDM4. In the report, there are 7 types of emissions, which have been mentioned in Introduction (Chapter 1). Analyzed by HDM4, the detailed quantity of vehicle emissions for the typical road section is shown as Fig.2 (A), (B) and (C).

According to these data, it is apparent that almost all the vehicle emissions under poor, fair and good maintenance (except for Lead) decreases over these 20 years. Carbon dioxide accounts for about $95 \%$ of total amount of vehicle emissions, following by carbon monoxide which only accounts for approximately 3\% of total emissions. The proportion of lead emissions is the least among all the emissions. It also proves that climate change has been a threat due to the quantity of carbon dioxide emissions by vehicle.

In addition, the change tendency of each vehicle emissions is similar. For example, almost all the emissions under good maintenance slightly increases in 2025 and 2030. Hence, the change tendency of total emissions can also represent the one of each type of emissions. Calculated by Excel, the total amount of vehicle emissions can be obtained and the change tendency is presented as the Fig. 3.

It is concluded from the figure that the total emission under poor, good and fair maintenance are entirely the same from 2015 to 2024, while the amount and change tendency are various after 2024. This is similar to the change trend of roughness over analysis period. According to the figure, 
at the end of the analysis period, the amount of total vehicle emission under good maintenance is the minimum, while the one under poor maintenance is the maximum and the quantity of vehicle emissions under fair maintenance is between these two values.

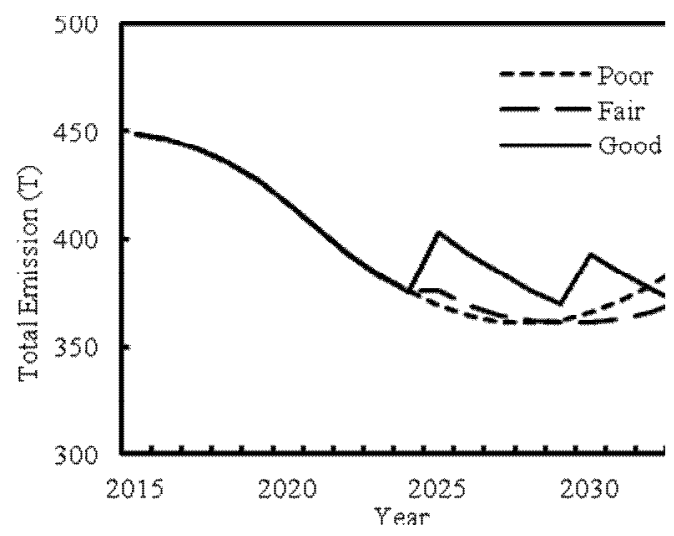

Fig. 3 the Amount of Total Emissions for "Traffic-One" Section under Poor, Good and Fair Maintenance

Although vehicles on good maintenance road will generate least emissions in 2034 or after 2034, when considering the total emission amount through the analysis period, things may be different. The total emission amounts over 20 years for the three maintenances (Poor, Fair and Good) are 7892.70, 7844.66 and 7988.89 in tonnes respectively. Vehicles on good maintenance road will produce the most emissions, while the one on fair maintenance road will generate the least emissions and emission amount under poor maintenance has the moderate value. This result is totally different from the vehicle emission amount in 2034.

Comparing Fig. 3 with Fig. 2, it is apparent that the emission amount sharply increases when roughness significantly decreases in 2025 and 2030 for good maintenance. It is because that the roughness can influence the vehicle travelling speed. Low roughness with high travelling speed will lead to more vehicle emission. However, when roughness is larger enough over 10.2 IRI according to poor and fair maintenance, though it will result in low vehicle traveling speed, the vehicle emission will also slightly increase due to the effect of roughness on fuel consumption.

\section{Discussion and Conclusion}

Higher road roughness are associated with higher vehicle emission.[5][6] In addtion, travelling speed is positively related to vehicle emission.[7] Both these two factors can be inflenced by maintenance work. Good maintenance vitally reduces the roughness, however, the trafflic speed will be high due to low roughness if without speed limit. Hence, the amount of vehilce emission from good maintenance road will be significant. Poor maintance lead to the high roughness after a certain time. Although the travelling speed is low, the amount of vehicle emssion from poor maintence will also be large when the roughness is high enough. Considering the effects of speed and roughness, fair maintenance is the best for controlling vehilce emission.

According to the figure, it is noticed that there is a lowest emission point in 10.2 IRI point which is assumed as the "balance point" of effect of roughness and traffic speed. It is supposed that the ideal maintenance is to remain the vehicle emission around the "balance point". Reducing traffic volume, limiting speed and traveling on a straight and level road can also decrease the vehicle emission. 


\section{References}

[1] Department for Energy and Climate Change: 2013 UK Greenhouse Gas Emissions (National Statistics publication, UK 2015)

[2] HDM Global: HDM4 Version 2. http://www.hdmglobal.com

[3] P. Chandrama, K. S. Aravind, and T. Geetam: Procedia - Social and Behavioral Sciences, Vol.104 (2013), p. 274

[4] B. Christopher: HDM4 Manual Volume 7. http://moodle.stoa.usp.br

[5] K. Celine J. Mansoureh and S. Anthony: submitted to TRB 2012 Annual Meeting (2011)

[6] G. Suzanne, A. Mehdi, U. Frank-Josef and G. Jeremy: http://www.rmc-foundation.org

[7] F. Malcolm: Malcolm Fergusson. Vol. 22 (1994), p. 103 